\title{
Investigation of energy absorption of a GFRP composite crash box
}

\author{
H. Ghasemnejad, H. Hadavinia \& A. Aboutorabi \\ Faculty of Engineering, Kingston University, SW15 3DW, UK
}

\begin{abstract}
Interlaminar fracture toughness of composite materials plays an important role on the specific energy absorption (SEA) of the crushing of composite materials. In this regard an optimum composite crash box design is sought by studying the effect of fibre orientation and stacking sequence on the increase of interlaminar fracture toughness. In order to achieve this, various glass fibre/epoxy orientations were studied experimentally. Double Cantilever Beam (DCB) and axial crush box specimens were made and tested in a quasi-static condition to determine the interlaminar fracture toughness $\left(G_{I C}\right)$ and SEA values for each set of fibre orientation and stacking sequence. The effect of the stacking sequence on fracture toughness and the SEA of the GFRP composite crash box has been quantified and optimum results were obtained.
\end{abstract}

Keywords: interlaminar fracture toughness, specific energy absorption, fibre orientation, stacking sequence, composite.

\section{Introduction}

The high energy absorbing capabilities of fibre reinforced polymer composite (FRP) materials is one of the main factors in their application in automotive and aerospace structures, while they also provide other functional and economical benefits such as enhanced strength, durability, weight reduction and lower fuel consumption. For structural vehicle crashworthiness, FRP composites are able to collapse in progressive a controlled manner, which results in high specific energy absorption in the event of an unexpected crash. Unlike metals and polymers, the progressive energy absorption of composite structures is dominated by extensive micro-fracture instead of plastic deformation [1-3]. Various fracture mechanisms such as fibre breakage and buckling, matrix 
cracking and crushing, debonding at the fibre-matrix interface and especially plies delamination play important roles on progressive failure mode and energy absorption of composite tubes. Cauchi Savona and Hogg [4] studied the relation between sustained crushing stress of glass fibre reinforced plastic composite plates with their Mode-I and Mode-II fracture toughness properties. According to their results, materials that show low Mode-I and Mode-II fracture toughness yield low crushing energies. Solaimurugan and Velmurugan [5] have recently studied the effect of stitching, fibre orientation and stacking sequence on $G_{I C}$, SEA, and progressively crushing of glass/polyester composite cylindrical shells under axial compression. They reported that axial fibres placed close to the outer surface of the tube lead to more petal formation and stable crushing process, while axial fibres close to the inner surface tube cause higher energy absorption. The present work is mainly focused on the effect of fibre orientation and stacking sequence on $G_{I C}$ and SEA. The DCB and crash box specimens were made and tested with different lay-ups but with the same geometry and material. The experimental results were compared together to find the relationship between $G_{I C}$ and SEA.

\section{Experimental studies}

Five different types of tests were conducted to characterize the mechanical characteristic of GFRP material. These were tensile, shear, double-cantilever beam (DCB), volume fibre fraction and quasi-static crush box. All tensile, shear, DCB and volume fibre fraction tests were carried out in accordance with the relevant ASTM standards. All specimens were manufactured from glass fibre material of density $2.1 \mathrm{~g} / \mathrm{cm}^{3}$ with epoxy resin. A summary of the findings from these tests are reported in table 1.

Table 1: $\quad$ Material properties of the GFRP.

\begin{tabular}{|c|c|c|c|c|c|c|c|}
\hline$E_{1}$ & $E_{2}$ & $G_{12}$ & $v_{12}$ & $\begin{array}{c}\text { UTS 0 } \\
\mathbf{( M P a )}\end{array}$ & $\begin{array}{c}\text { UTS 90 } \\
\mathbf{( M P a )}\end{array}$ & $\begin{array}{c}\text { Shear } \\
\text { Strength } \\
\mathbf{( M P a )}\end{array}$ & $\begin{array}{c}V_{f} \\
\mathbf{( \mathbf { G P } )}\end{array}$ \\
\hline 35.1 & 9.6 & 4 & 0.32 & 807 & 21.3 & 97.9 & 40.3 \\
\hline
\end{tabular}

The lay up of DCB specimens were similar to the laminate design of composite crush boxes. The mid-plane interfaces were 0/90, 90/90, 0/45 and $+60 /-60$ to determine the Mode-I interlaminar fracture toughness. Four laminate with fibre orientations of $[ \pm 60]_{10},\left[0_{2}, \pm 45\right]_{5},[0,90]_{10}$ and $[0,90]_{5 \mathrm{~s}}$ were chosen for composite boxes. The 0 direction coincides with the axial axis of the crush box. Each specimen was crushed between two parallel plates for a $50 \mathrm{~mm}$ stroke using a Universal Testing Machine with a $500 \mathrm{kN}$ load cell, see fig. 1 . The crush speed was set at $2 \mathrm{~mm} / \mathrm{min}$, the same as the one used in DCB tests. For each test configuration three specimens were tested. The force-crush distance diagrams were recorded automatically for each test. 

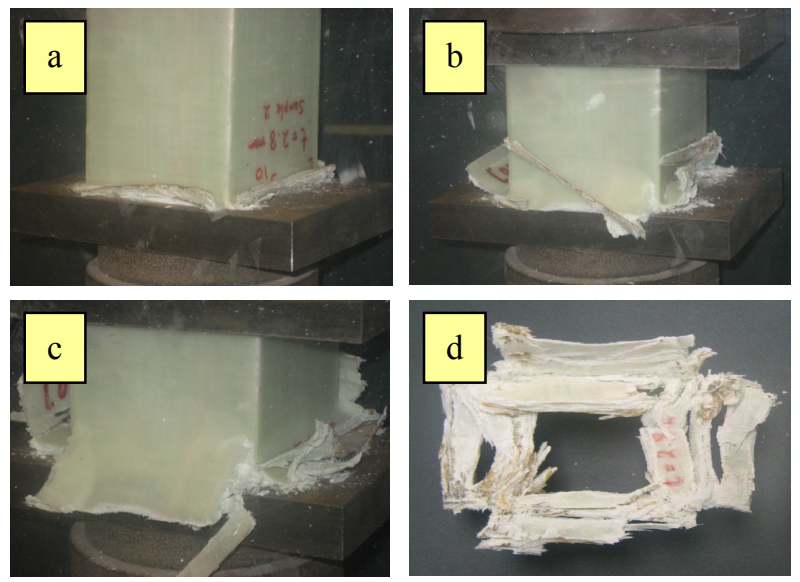

Figure 1: Various crushing processes of the GFRP composite box between two plates.

\section{Results and discussion}

\subsection{Mode-I interlaminar fracture toughness}

The Mode-I interlaminar fracture toughness $G_{I C}$, for each fibre orientation was calculated using the Modified Beam Theory (MBT) method and the Modified Compliance Calibration (MCC) method [6-9]. For the MBT method, the cube root of compliance, $C^{1 / 3}$, was plotted as a function of crack length, $a$. The intercept with the $\mathrm{x}$-axis was considered as the crack length correction, $\Delta$. The $G_{I C}$ was calculated from:

$$
G_{I C}=\frac{3 F \delta}{2 b(a+|\Delta|)}
$$

In the MCC method a least squares plot of $a / t$ as a function of the cube root of the compliance, $C^{I / 3}$, is generated using the visually observed delamination onset values and all the propagation values. The slope of this line is A [9]. The $G_{I C}$ was then obtained from:

$$
G_{I C}=\frac{3 F^{2} C^{2 / 3}}{2 A b t}
$$

where $\mathrm{F}$ is force, $\mathrm{b}$ is the width of specimen and $\mathrm{t}$ is thickness.

The experimental $G_{I C}$ results obtained from the MBT and MCC for different fibre orientations are shown in table 2. A sample experimental resistance curve versus crack length is shown in fig. 2. 
Table 2: Interlaminar fracture toughness obtained from DCB tests for various interface fibre orientations.

\begin{tabular}{|c|c|c|c|}
\hline Laminate lay-up & $\begin{array}{c}\text { Fracture } \\
\text { plane } \\
\text { interface }\end{array}$ & $\begin{array}{c}\boldsymbol{G}_{\boldsymbol{I C}} \\
\left(\mathbf{k J} / \mathbf{m}^{\mathbf{2}}\right) \\
\mathbf{M C C}\end{array}$ & $\begin{array}{c}\boldsymbol{G}_{\boldsymbol{I C}} \\
\left(\mathbf{k J} / \mathbf{m}^{\mathbf{2}}\right) \\
\mathbf{M B T}\end{array}$ \\
\hline$[\mathbf{0 , 9 0}]_{\mathbf{1 0}}$ & $0 / 90$ & 0.923 & 1.243 \\
\hline$\left[\mathbf{0}_{\mathbf{2}, \pm \mathbf{4 5}}\right]_{\mathbf{5}}$ & $0 / 45$ & 0.884 & 1.060 \\
\hline$[\mathbf{0 , 9 0}]_{\mathbf{S}}$ & $90 / 90$ & 0.778 & 1.168 \\
\hline$[ \pm \mathbf{6 0}]_{\mathbf{1 0}}$ & $+60 /-60$ & 0.449 & 0.541 \\
\hline
\end{tabular}

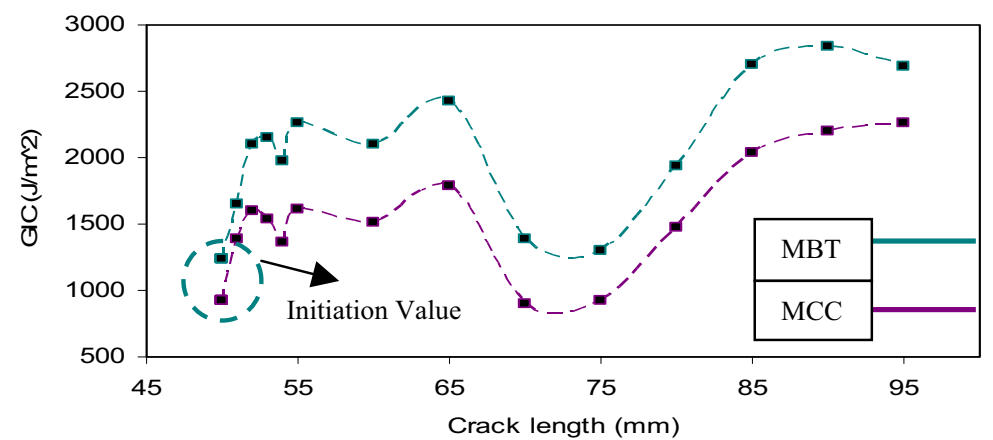

Figure 2: $\quad$ Resistance curve (R-curve) in a DCB specimen with a 0/90 fracture plane interface using the MBT and MCC methods.

Transverse cracking of $\theta$-oriented lamina at the interface caused some fibre bridging for most of DCB tests as shown in fig. 3. The development of fibre bridging caused the force to continuously increase as the crack advanced resulting in an R-curve. According to the results and recommendations from other works on DCB-tests on multidirectional laminates $[10,11]$, initiation $G_{I C}$ values were considered as interlaminar fracture toughness. There are three different methods to determine the initiation of crack growth from the precrack. The first one is the non-linearity (NL) method, which is the point of deviation from linearity, by sketching a straight line from the origin on the loaddisplacement diagram. The second method is visual observation (VIS), which is the first point at which the crack is observed to move from the tip of the Teflon insert. The last one is $\mathrm{MAX} / 5 \%$, a point on the force-displacement curve at which the compliance has increased by $5 \%$ of its initial value. In this work the visual observation (VIS) was chosen to determine the initiation crack length. It was observed that fibre orientation in the layers adjacent to crack plane affects the $G_{I C}$. Mode-I interlaminar fracture toughness of interface layers of $(0 / 90)$ showed the highest amount for all tested specimens, and the interlaminar fracture toughness of interface layers of $(+60 /-60)$ showed the lowest value. The combination of $0 / \theta$ and $\theta / \theta$ at interface layers caused the maximum interlaminar fracture toughness. 


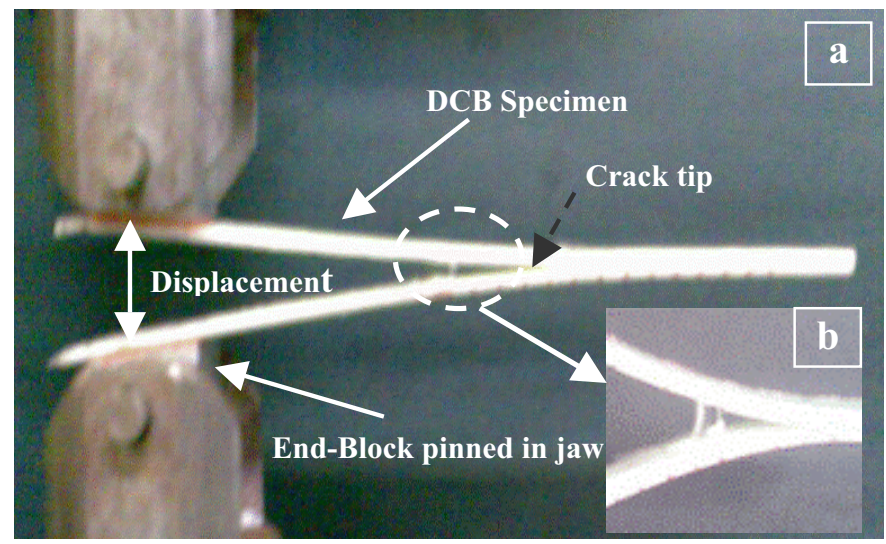

Figure 3: a) GFRP DCB test specimen in universal testing machine, b) Fiber bridging across the interface layers.

\subsection{Progressive crushing process}

Three main crushing modes are categorised for progressive failure of the composite box in the crushing process. The first one is fragmentation mode, which is characterised by a wedge-shaped laminate cross section with one or multiple short interlaminar and longitudinal cracks. The second one is lamina bending mode, which is shaped with long interlaminar, intralaminar, and parallel to fibre cracks. This mechanism causes the formation of continuous fronds that spread inwards and outwards. The third one is the combination of fragmentation and lamina bending modes and it is called brittle fracture mode. Different modes of crush were observed during the quasi-static crush test. As can be seen in fig. 1, the combination of two distinct crush modes, fragmentation and lamina bending, were observed for all the specimens. This mode that is called brittle fracture is an ideal crushing mechanism to dissipate the energy during crushing in composites. For fibre orientation of $[0,90]_{5 \mathrm{~S}}$ and $[ \pm 60]_{10}$, the fronds were broken into short peaces. The other two fibre orientations $\left[0_{2}, \pm 45\right]_{5}$ and $[0,90]_{10}$ showed more interlaminar separation in the crushing process. The main central crack, which causes shaping of lamina bundles, has an important role in resistance against crushing energy.

The propagation of this crack is similar to the crack propagation in Mode-I delamination in composite laminates discussed earlier in section 3.1, in that the fibre orientation at the interface planes has a significant effect on Mode-I interlaminar fracture toughness. The SEA also varies with fibre orientation and fracture behaviour of the main interlaminar cracks. These evidences show that the fracture behaviour of a central interlaminar opening crack is correlated to Mode-I interlaminar fracture toughness, see fig. 4. 


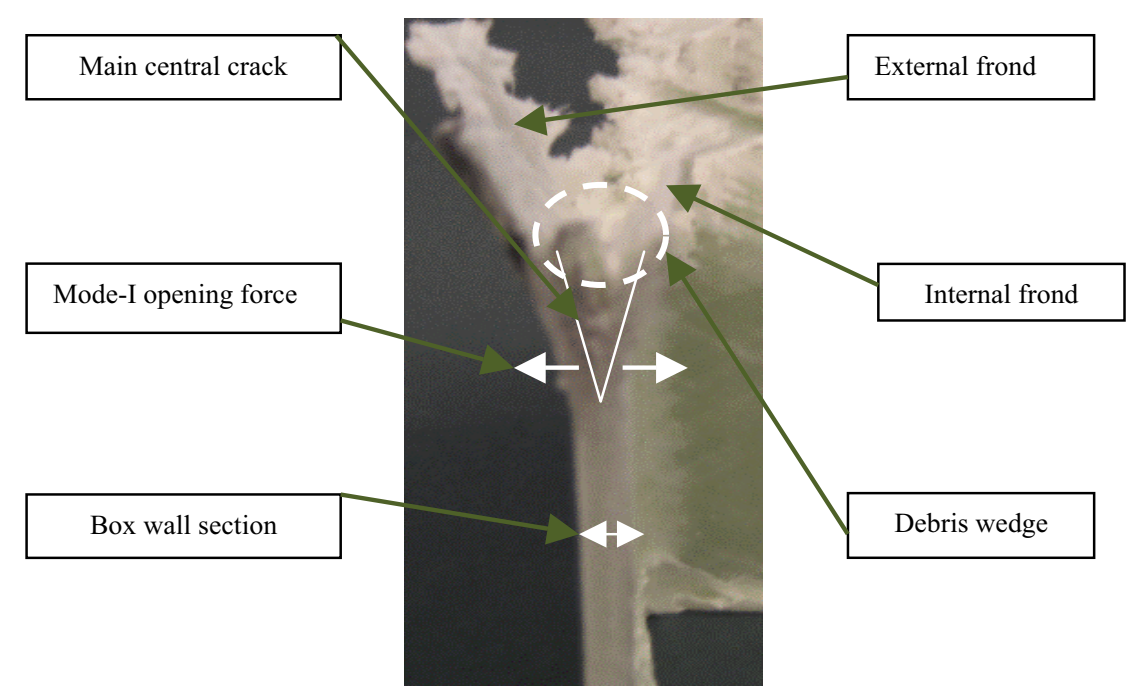

Figure 4: Mode-I interlaminar crack propagation at the middle of the box wall.

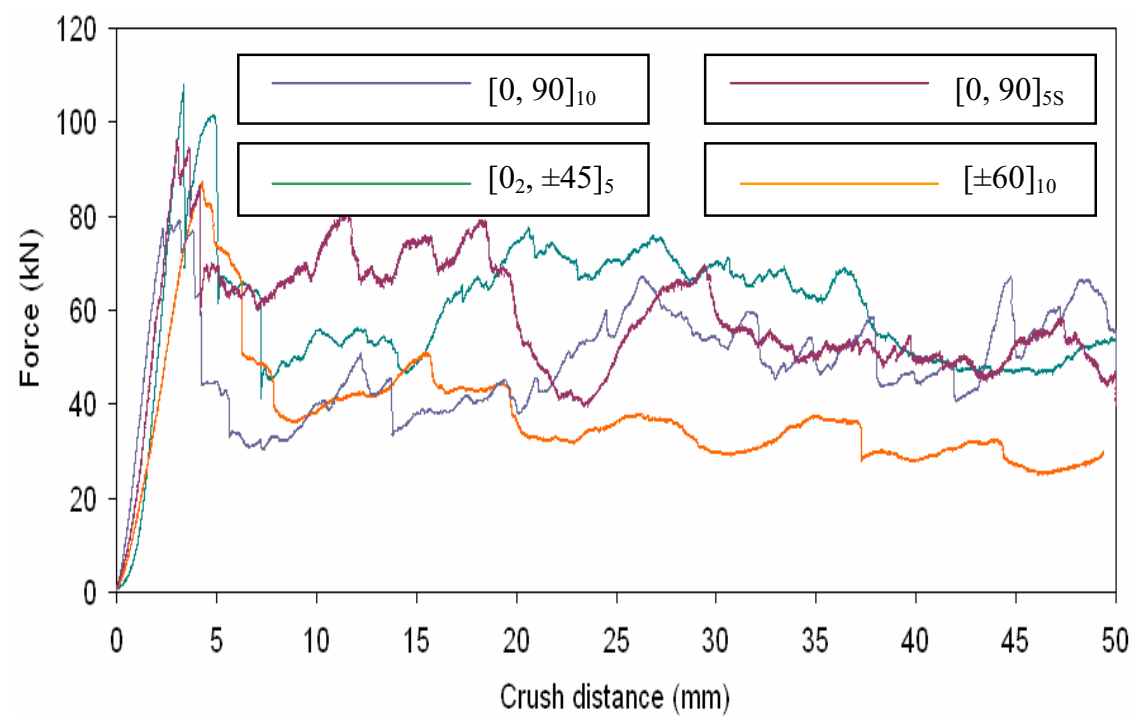

Figure 5: Comparison of force-crush distance in a square crash box for various lay-ups.

The comparison of experimental results of force-crush distance for all lay ups are shown and compared in fig. 5. The results show that the $\left[0_{2}, \pm 45\right]_{5}$ has the highest mean force and consequently highest energy absorption in comparison with other lay-ups. This high energy absorption is related to high Mode-I 
interlaminar fracture toughness. The lowest interlaminar fracture toughness from the DCB tests was observed for the $[ \pm 60]_{10}$ lay-up. This is reflected in the lowest mean force and energy absorption in the crash box with the same lay-ups. The variation of specific energy absorption (SEA) from crush test versus Mode-I interlaminar fracture toughness, $G_{I C}$, from DCB tests for various lay-ups is plotted in fig. 6. It can be seen that the interlaminar fracture toughness for interface fracture planes of $0 / 90,90 / 90$ and $0 / 45$ are close together while $+60 /-$ 60 interface plane is far apart. This shows that the specific energy absorption (SEA) of fibre orientations, which are laminated with $0 / \theta$ angles, are close together.

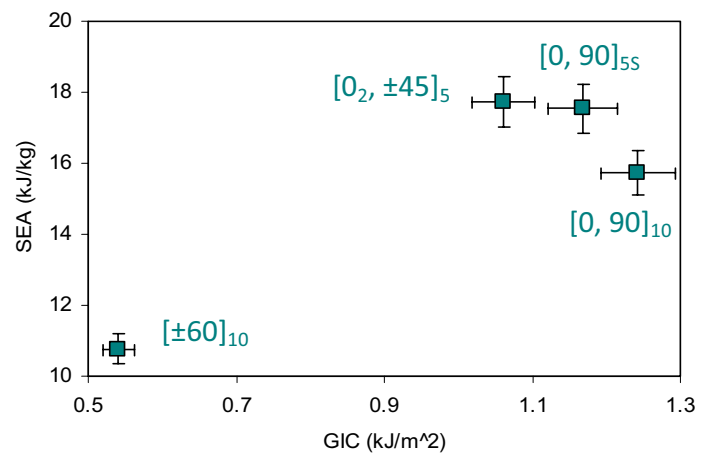

Figure 6: Variation of specific energy absorption (SEA) with interlaminar fracture toughness, $G_{I C}$ for various box lay-ups.

\section{Conclusion}

In this paper, the effect of fibre orientation on interlaminar fracture toughness, $G_{I C}$, and specific energy absorption, SEA, of the GFRP composite crush box was investigated. Our studies show that:

- Fibre orientation at the interface fracture plane affects the interlaminar fracture toughness of the GFRP composite materials.

- Interlaminar fracture toughness for interface fracture planes of $0 / 90$, $90 / 90$ and $0 / 45$ are close together while $+60 /-60$ behave differently.

- The interface plane of 0/90 showed the maximum interlaminar fracture energy, and $+60 /-60$ interface laminate design showed the minimum value.

- $\quad$ SEA in the axial crush of a composite box depends on the interlaminar fracture toughness between laminates. The higher the Mode-I fracture toughness, the higher the SEA. However this relationship is not linear.

- The SEA of those fibre orientations that have a combination of $0 / \theta$ angles are close together because of the similar interlaminar fracture toughness at the interface fracture plane. 
- By choosing a suitable laminate design for crushing composite structures, the interlaminar fracture toughness and consequently the SEA can be improved.

\section{Acknowledgement}

The authors wish to acknowledge financial support from the Institution of Mechanical Engineers (IMechE) through a Thomas Andrew Commons Grant.

\section{References}

[1] Hull, D., A unified approach to progressive crushing of fibre reinforced tubes. Composite Sci. Technol. 40, pp. 377-421, 1991.

[2] Farley, G. \& Jones, R., Crushing characteristics of continuous fibre reinforced composite tubes. Journal of Composite Materials, 26, pp. 37-50, 1992.

[3] Mamalis, A.G., Manolakos, D.E., Demosthenous, G.A. \& Ioannidis M.B., The static and dynamic collapse of fibreglass composite automotive frame rails. Composite Structures, 34, pp. 77-90, 1996.

[4] Cauchi Savona, S. \& Hogg, P.J., Effect of fracture toughness properties on the crushing of flat composite plates. Compos Sci Technol, 66, pp. $2317-$ 2328, 2006.

[5] Solaimurugan, S. \& Velmurugan, R., Influence of fibre orientation and stacking sequence on petalling of glass/polyester composite cylindrical shell under axial compression. Int Jnl of Sol and Struc, 44, pp. 6999-7020, 2007.

[6] Blackman, B.R.K. \& Brunner, A.J., Mode I fracture toughness testing of fibre reinforced polymer composites: unidirectional versus cross ply lay up, In: Brown MW, de la Rios ER, Miller KJ., editor, ECF-12 Fracture from Defects, EMAS, pp. 1471-1475, 1998.

[7] Hashemi, S., Kinloch, A.J. \& Williams, J.G., The analysis of interlaminar fracture in uniaxial fiber-polymer composites, P Roy Soc Lond A Mat, 427, pp. 173-199, 1990.

[8] Williams, J.G., End corrections for orthotropic DCB specimens, Compos Sci Technol, 35, pp. 367-376, 1989.

[9] Shetty, M.R., Vijay Kumar, K.R., Sudhir, S., Raghu, P. \& Madhuranath, A.D., Effect of fibre orientation on Mode-I interlaminar fracture toughness of Glass Epoxy composites. Journal of Reinforced Plastic and Composites, 19, pp. 606, 2000.

[10] Choi, N.S., Kinloch, A.J. \& Willams, J.G., Delamination fracture of multidirectional carbon-fiber/epoxy composites under mode I, mode II and mixed mode I/II loading. J Compos Mater, 33(1), pp. 73-100, 1999.

[11] de Morais, A.B., Double cantilever beam testing of multidirectional laminates. Compos Part A: Appl Sci, A34(12), pp. 1135-42, 2003. 